\title{
La cultura puertorriqueña en la gerencia de los recursos humanos
}

\author{
Carmen I. Figueroa \\ Universidad de Puerto Rico, Mayagüez
}

\section{Resumen}

La relevancia de la cultura puertorriqueña en la gerencia de los recursos humanos se encuentra en un momento definitivo debido a la crisis de actitudes y valores en la cultura de trabajo, así como el servicio en las organizaciones en Puerto Rico. Este artículo aborda la entrevista realizada al Dr. Justo Méndez Colón que advierte acerca de los renglones que debe considerar el gerente de recursos humanos en Puerto Rico para el cambio de conducta y la transformación de la cultura de trabajo. En términos más generales, el artículo menciona la definición de cultura, la preeminencia de la cultura puertorriqueña en la gerencia de los recursos humanos, la oportunidad del desarrollo de una conciencia cultural en el lugar de trabajo y la polémica para alcanzar la alineación de la cultura puertorriqueña en las organizaciones.

\section{Palabras claves}

Cultura, gerencia, recursos humanos, trabajo

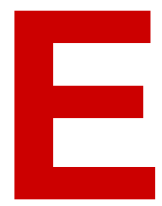

n entrevista realizada al Dr. Justo Méndez Colón, catedrático jubilado del Recinto de Río Piedras de la Universidad de Puerto Rico, abordó el tema de la cultura puertorriqueña en la gerencia de los recursos humanos. El aumento en la crisis de actitudes y valores en la cultura de trabajo y servicio en las organizaciones en Puerto Rico es determinante.

Como educador, sociólogo y consultor en la conducta humana, específicamente, en el estudio de la cultura puertorriqueña, ha sido reconocido por sus ejecutorias académicas y profesionales. ¿Cuáles fueron sus motivos al seleccionar la cultura puertorriqueña en sus estudios superiores?

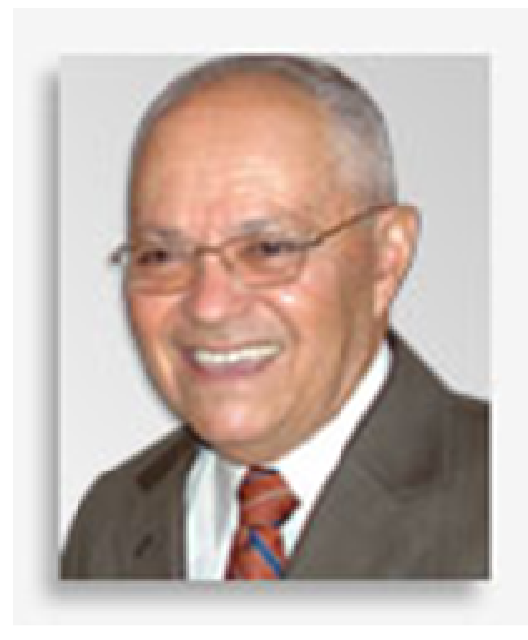

"He pasado una buena parte de mi vida académica estudiando el tema en todas sus vertientes", apuntó Méndez Colón. Es evidente que ha dedicado aproximadamente 60 años de vida, empeño y voluntad investigando en colecciones universitarias, archivos públicos, recuerdos, experiencias de vida, entre otros. "Con humildad y orgullo la vida me ha dado la oportunidad de aumentar nuestro arsenal de conocimiento y argumentos contra el tiempo, el olvido, los enemigos de nuestra identidad y a favor del esclarecimiento de lo que llamo ese proyecto colectivo que nos libera, más allá de lazos, banderías y cadenas políticos", agregó el célebre educador y sociólogo. 
Sin embargo, Méndez Colón aclaró que jamás ha sido gerente, supervisor y que de ningún modo ha tenido la oportunidad de supervisar algún talento humano que no sea él mismo. "El único proyecto de vida que he dirigido, supervisado, es la mía propia, las riendas de mi vida que me ha permitido alcanzar la felicidad humana. A falta de padres, la vida me ofreció maestros, en medio de la pobreza vil y abyecta de aquel Puerto Rico de las décadas treinta, cuarenta y cincuenta. Me tocó desde, sufrir la tragedia del suicidio entre mis padres cuyo resultado concurrió en quedarme sin hogar y vivir en las calles de mi país", manifestó Méndez Colón. Afirmó que las circunstancias de su vida son ejemplo de la superación del paradigma de un talento humano que obtuvo calificaciones excelentes desde la escuela superior hasta culminar un grado doctoral. "La formación de mi proyecto de vida, de conocerse a sí mismo como una buena persona, con el atributo de la inteligencia, con el ánimo de superación y mirando el camino de la vida hacia adelante" declaró Méndez Colón.

En un sentido amplio, considerando su dedicación hacia el estudio de la cultura puertorriqueña, ¿cómo definiría el término "cultura"?

"La cultura, en su sentido más amplio, como actitud de una comunidad, como la trabazón de maneras de vivir la vida, un grupo humano. En un sentido más especializado, cultura es esa serie de disciplinas intelectuales y espirituales, conscientes, de un grupo que se supone preparado para tales disciplinas en una comunidad. Tratan de extender la comprensión, la efectividad del pensamiento y de las fuerzas espirituales con intención de aclarar, fortalecer, variar y perfeccionar la actitud hacia la vida que ha desarrollado una comunidad. Este escenario obedece a las múltiples fuerzas incluyendo, predominantemente, las fuerzas no dirigidas que han hecho su desarrollo", sostuvo Méndez Colón.

"Es decir, la cultura en su sentido más amplio es la actitud hacia la vida y maneras de existir de una comunidad, actitud mala o buena, inteligente o torpe, pero real $\mathrm{y}$ espontánea-desarrollada por esa comunidad en el proceso de su formación como tal y en los antecedentes que precedieron a la iniciación de este proceso", expresó Méndez Colón. Añadió que la cultura en el sentido especializado, es el espíritu humano, el propósito de la conciencia, la imaginación y la comprensión. Además, el educador y sociólogo enfatizó que es la inteligencia para establecer las variantes de superación en la actitud de esa comunidad hacia la vida. También destacó la manera de vivir la vida que representa la superación en la cultura, en el sentido más amplio de esa comunidad.

Ante el escenario actual en Puerto Rico debido al aumento en la crisis de actitudes y valores, ¿cuán relevante es la cultura puertorriqueña en la gerencia de los recursos humanos?

Méndez Colón advirtió que es vital para los gerentes de recursos humanos el entendimiento de nuestra cultura. Además, recalcó la importancia de nuestra competitividad, la superación así como el ingrediente de la felicidad misma de cada uno que se convierte en recurso humano y de igual manera de cada uno que llega a ser gerente de nuestro país. "La gerencia significa administración, dirección, manejo, gestión, autoridad, conducción”, indicó Méndez Colón. Afirmó que "en fin, todo lo que necesita un ser humano que llamamos gerente para descargar una responsabilidad 
que aceptó". "Cuando decimos recurso humano, nos estamos refiriendo a ese ser que quisiéramos convertir en el activo más importante de la empresa, cualquiera que sea: desde la farmacéutica que produce el medicamento para tratar una enfermedad catastrófica, hasta el padre o madre que dirigen una familia, en medio de esta crisis de valores que nos agobia a todos", expuso.

También, Méndez Colón acentuó que "la realidad de hombres y mujeres puertorriqueñas con actitudes, valores, comportamientos y cultura, en experiencia viva, profunda, sistemática y práctica, capaces de conocerse, entenderse, comprenderse hasta la posibilidad del impulso de estrategias para el desarrollo humano, así como el crecimiento del conocimiento". Dando énfasis a nuestra realidad y no desde realidades inventadas, añadió que "ello lo consideramos cierto a todos los niveles de ejecución: empleados, unionados, gerenciales y directivos". Méndez Colón exhortó que la gerencia puertorriqueña debe capacitarse para poder competir hacia la superación. "Ello incluye, desde luego, la vinculación de estos elementos con la sociología de la productividad y de rentabilidad en las organizaciones de todas clases en Puerto Rico", expresó Méndez Colón. "Después de investigar, escudriñar y trabajar con estos temas y con un número considerable de organizaciones, argumentamos empíricamente que hay una fuerte relación entre las actitudes, los valores y los comportamientos de productividad que despliegan los puertorriqueños en el escenario de trabajo", puntualizó.

¿Es posible desarrollar una conciencia cultural en la gerencia de los recursos humanos en Puerto Rico?
Específicamente, Méndez Colón enfatizó que compartimos una disciplina particular que explica en detalle los fundamentos del desempeño, la ejecución y productividad de las organizaciones en Puerto Rico. "La gerencia de recursos humanos debe establecer el vínculo entre la gente, las estrategias y las operaciones como tres procesos medulares que influyen en la calidad y la cantidad de los resultados que se obtienen en el lugar de trabajo", resaltó Méndez Colón. Especificó que la gerencia de los recursos humanos era responsable de adiestrar y desarrollar a todos los niveles en la organización. Además, recalcó acerca de la conciencia para ejercer el liderazgo y desempeñar un papel de gerente o de supervisor al conocer los antecedentes, los procesos, así como las consecuencias de las actitudes y valores en el comportamiento cotidiano. "Es la responsabilidad de todos los líderes y profesionales que trabajan en una organización entender a cabalidad los fundamentos del desempeño y la ejecución que es capaz de producir resultados hacia la superación y la competitividad. En la medida que se logra la conciencia individual y colectiva, entonces la organización va creando una cultura de inteligencia emocional y técnica que permite promover niveles más elevados y superiores de productividad organizacional", subrayó.

¿De qué manera la cultura puertorriqueña aporta a la comprensión entre actitudes, valores y comportamientos de los recursos humanos?

Según ha señalado el sociólogo y educador Méndez Colón, un acercamiento profundo, dinámico $\mathrm{y}$, sobre todo, interactivo a la literatura, a la historia y la cultura puertorriqueña ayuda a explicar la relación entre actitudes, valores y comportamientos. "La gerencia de recursos humanos debe considerar la creación de una 
dinámica y un diálogo formativo para diseñar modelos mentales necesarios para el cambio de comportamientos y para la transformación de la cultura de trabajo", destacó Méndez Colón. Aclaró que es necesario establecer las condiciones que hacen posible la sincronización de seres humanos, cultura de trabajo, estrategias de operaciones, en vías de responder a los reclamos externos de servicio que se recibe constantemente la organización. "Convertir al recurso humano en el principal activo de la empresa, esa es nuestra voluntad $\mathrm{y}$ empeño. El propósito de esta experiencia estriba en fortalecer y lograr la sustentabilidad de la cultura de productividad que es necesaria para la organización. A favor de esclarecer la cultura puertorriqueña, es necesario emprender la búsqueda de aquel tiempo pasado que ofrece tantas ideas, además añoranzas $\mathrm{y}$ recuerdos que producen felicidad", declaró.

¿Cuál es la polémica esencial que los gerentes de recursos humanos desafian ante la cultura puertorriqueña?

Méndez Colón cuestiona si los gerentes de recursos humanos conocen la cultura puertorriqueña. "Si examinamos el proceso cultural en Puerto Rico y como debería ser, se pudiera malograr la personalidad puertorriqueña", agregó. Afirmó que Puerto Rico se encuentra en una encrucijada, un momento histórico. "Los gerentes de recursos humanos deben considerar el deliberado proceso cultural de la pérdida de la personalidad puertorriqueña dónde se está escapando la vida y la identidad de los recursos humanos en la organización", expuso Méndez Colón. Destacó que la dificultad actual en la gerencia de recursos humanos para alinear la cultura puertorriqueña estriba en conocernos a nosotros mismos y citó al doctor Luis Nieves Falcón:

“...lo que le da substancia esencial a la cultura son los valores, los modos de ver el mundo y al hombre, y los comportamientos. En términos nuestros, representa esa estimación personal que le atribuimos en forma inherente al ser humano; ese dotarlo de una dignidad inminente sin importar la posición que le ha tocado desempeñar en una etapa particular de la vida; en despojarse de lo propio y lo necesario para mostrar agradecimiento; en la consideración exagerada que mostramos por no herir la sensibilidad ajena; en personalizar la vida propia y única en aras de las demandas familiares. "1.

A tales efectos, Méndez Colón enfatizó que el escenario actual en Puerto Rico ha agravado la alineación entre la cultura y la gerencia de los recursos humanos. "En Puerto Rico, la falta de definición, inestabilidad en su carácter, la confusión en los marcos de referencia es evidente en la

\footnotetext{
${ }^{1}$ Nieves, L. (1972). Diagnóstico de Puerto Rico (2da ed.). Río Piedras, PR: Editorial Edil.
} 
formación de la cultura puertorriqueña desde antes de los años treinta", señaló Méndez Colón. Expresó que el recurso humano en Puerto Rico se ha desvinculado más de nuestras raíces. Agregó que se ha entregado al servicio de los intereses del mercado amenazando los conocimientos de la conducta humana. También, mencionó la descomposición de la racionalidad, así como la seducción hacia un pensamiento que directamente nos dirige y favorece a la estructura de poder en un momento determinado. "Ante la crisis de actitudes y valores actual, la cultura puertorriqueña se encuentra ante una oportunidad única y un momento histórico de reestructuración, fortalecimiento y crecimiento", exhortó.

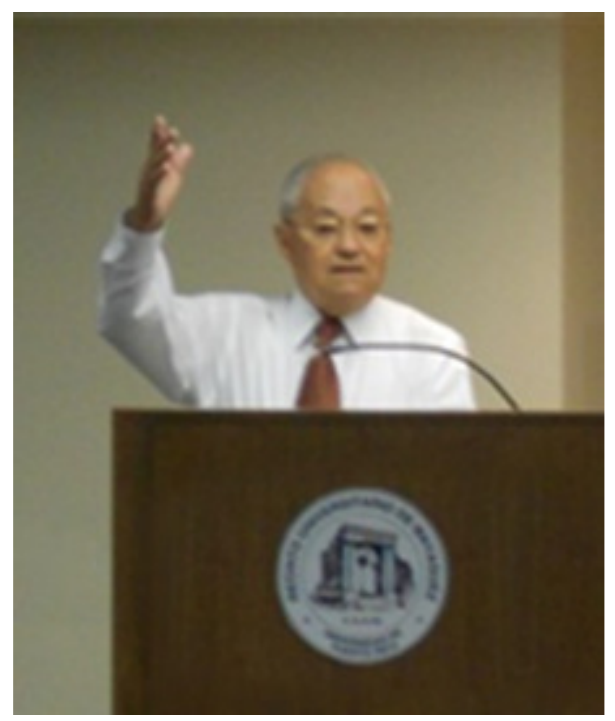

Ante la crisis de actitudes y valores actual, ¿qué les propone a los gerentes de recursos humanos para alcanzar la alineación con la cultura puertorriqueña en las organizaciones?

"Tenemos que enamorarnos de esa búsqueda de aquel tiempo pasado, que ofrece tantas ideas, además de añoranzas y recuerdos que producen felicidad. El ejercicio de reflexionar nos permitiría considerar una realidad distinta, unos errores que se cometieron entonces, una investigación social y su resultante planificación y, sobre todo, unas concepciones teóricas y otros métodos de mayor poder político", resaltó Méndez Colón. Advirtió que en la búsqueda de los resultados pensados, no se pueden limitar recursos, ni económicos, ni de tiempo. "Proponemos los mejores talentos que se puedan adquirir en el país, para que nos ayuden en el desarrollo de nuestros recursos humanos, que queremos convertir en el activo que más rinda para el logro de nuestra misión, visión y aspiración. Reclutaremos talento, compromiso, dedicación, idoneidad, patriotismo, por qué no, entendimiento, aptitud, comprensión", destacó. Además, señaló que el escenario debe considerarse en un marco del poder para hacer el análisis de claridad meridiana de lo que estamos soñando cuando hablamos de cambio, ética en el taller de trabajo, mística del servicio, moral personal y social, autoestima, competitividad, superación y búsqueda de la felicidad, mediante el trabajo nuestro de cada día. "Tengo la responsabilidad de señalar la gran tarea que les propongo realizar a los gerentes de recursos humanos en Puerto Rico, entendiendo perfectamente que la tarea de realizarlo es más dura aún. Luego de reclutar esos talentos humanos, capaces de acompañar a los gerentes en esta responsabilidad, inscribir entre ambos, el entendimiento y el respaldo de nuestros recursos humanos, a quienes les corresponderá el deleite del servicio de excelencia que soñamos", sostuvo Méndez Colón. Añadió que la amenaza en la alineación de la cultura en la gerencia de los recursos humanos estriba en el esquema de enfrentarse al hombre, al otro ser humano con quién le toca interaccionar. Las presiones sociales que puedan imponer un cambio del anonimato perpetuo, la impersonalidad diaria y la desvinculación afectiva con sus semejantes. "El aumento en 
la evasión del puertorriqueño de su humanidad y su sentido de responsabilidad con los demás seres humanos. Por ello, no se siente la necesidad de compartir vivencialmente el infortunio de los semejantes, lo cual nos desvincula más aún de nuestras raíces. Nos convierte en útiles al servicio de los intereses de mercado y de la propaganda escandalosa que utilizan los conocimientos acerca de la conducta humana para embotarnos la racionalidad y persuadirnos a favor del modo de pensar que más conviene a la estructura de un poder determinado" reiteró.

¿Qué opina acerca del futuro de la cultura puertorriqueña en la gerencia de los recursos humanos?

"Desde ahora, me siento convencido, moral y emocionalmente, de que decir servicio es decir Puerto Rico. Y yo, consciente de que ese Puerto Rico tiene futuro, siento mi posibilidad más allá de una generación, más allá de lo individual, más allá del ciclo de vida de una organización", alentó Méndez Colón. Advirtió que muy pronto tendremos que decidir si seguimos la corriente que erradicará la cultura puertorriqueña, o si rehusamos darnos una oportunidad más que promueva la reestructuración, el fortalecimiento y el crecimiento de la comunidad geográfica y afectiva que es Puerto Rico. Méndez Colón culminó su exposición con la cita del laureado Luis Rafael Sánchez:

"Equilibradamente, alejados de los vicios de la patriotería pero cercanos a las virtudes del patriotismo, los puertorriqueños debemos conocer $y$ reconocer la grandeza de nuestro País en vez de caer en la desdicha moral de desmerecernos como individuos o la desgracia histórica de subestimarnos como colectividad. La grandeza puertorriqueña no hay que buscarla en el tamaño del País porque allí jamás se la encontrará. La grandeza puertorriqueña hay que buscarla en la gente puertorriqueña. Allí se guarda, como una dádiva transfigurada por la sencillez para satisfacción de quién decida quererse con responsabilidad y conocerse con iluminación. Allí aguarda humilde y limpia, como un vaso de agua fresca, a quién quiera disfrutarla",

Además, Méndez Colón manifestó que el conocimiento es poder y llegar a entender nuestro proceder histórico nos ubicaría en una ventaja competitiva estratégica para emprender con firmeza nuestro proyecto colectivo puertorriqueño. " $\mathrm{Al}$ entendimiento de esa identidad, cultura, historia, lengua tenemos que acercarnos confiados en el rescate de un conocimiento que dejaron unas mentes ilustres que lograron poner su mano en la rueda de la historia del país. Puerto Rico puede enriquecer su personalidad con el contacto de Estados Unidos y de la vida mundial sin dejar de ser Puerto Rico", sostuvo.

El Dr. Justo Méndez Colón es catedrático jubilado de la Facultad de Ciencias Sociales de la Universidad de Puerto Rico (por sus siglas, UPR), educador, sociólogo y consultor en conducta organizacional. En 1995 completó un Bachillerato en Artes en la Facultad de Pedagogía de la UPR. En el 1959 obtuvo una Maestría en Artes de la Universidad de Chicago con los grandes de la filosofía moderna. En el 1973 obtiene un Doctorado en Ciencias Políticas y Sociológicas con especialidad en cultura puertorriqueña de la Universidad Central de Madrid. A sus

\footnotetext{
${ }^{2}$ Sánchez, L. (1996, Julio 16). Grandeza puertorriqueña. El Nuevo Día, p. 15.
} 
lozanos 83 años, el Dr. Méndez Colón es considerado como uno de los oradores puertorriqueños más célebres de nuestra época.

\section{Carmen I. Figueroa Medina}

\section{carmen.figueroa11@upr.edu}

Instructora de la Escuela Graduada del Colegio de Administración de Empresas del Recinto Universitario de Mayagüez (por sus siglas, RUM) de la UPR, oficial de admisión graduada, educadora y asesora en gerencia de recursos humanos. En el 2000 completó una Maestría en Administración de Empresas del RUM de la UPR. En el 2011 obtuvo un Doctorado en Filosofía en Desarrollo Gerencial y Empresarial con especialidad en Gerencia de Recursos Humanos de la Universidad Interamericana de Puerto Rico. La Dra. Figueroa Medina ha realizado investigaciones para conferencias internacionales celebradas en Argentina, Ecuador, Estados Unidos, México, Perú, y Puerto Rico, entre otros. 